\title{
Slouching Toward a Theory of Names: A Tentative Taxonomic Fix
}

\author{
Wilbur Zelinsky \\ Pennsylvania State University
}

\begin{abstract}
Despite the accumulation of immense quantities of empirical treatments, the development of a genuine theory of names remains woefully mired at the primitive level of specifying the distinction between proper and common nouns. As an initial step forward, this paper sets forth, for the first time, a comprehensive taxonomy of the entire universe of names. In so doing, it draws attention to the many name-types that have been seriously or totally neglected as opposed to the inordinate amount of attention lavished on personal names and place names. Urgently needed is a single standardized classification system to be applied to the occurrences within each name-type. Such a standardization would render feasible meaningful cross-analysis among different cultural communities and historical periods as well as among name-types, thus laying the groundwork for posing serious theoretical questions.
\end{abstract}

The Need for, and Absence of, Theory

The theoretical scene in the study of names leaves everything to be desired. Such a situation smacks of the paradoxical, for, as Klaas Willems has stated, "Proper names are complex signs with specific linguistic, pragmatic, logical, philosophical, semiotic, historical, psychological, social, and juridical properties, and hence represent a vast interdisciplinary field of study" $(2000,86)$. Indeed "[t]he ramifications of naming are . . . vastly complicated, and [naming] represents a much larger segment of human activity than is usually recognized" (Stewart and Pulgram 1971, 1157). One could rationally expect, then, that such a far-reaching phenomenon, indeed the universal human propensity to name all manner of things, a practice with such enormous, far-reaching practical and intellectual implications, would long ago have inspired serious efforts to formulate a set of theories, large or small. 


\section{Names 50.4 (December 2002)}

Such formulations purport to explain the nature, origins, development, the essential meaning and larger import of the items at hand and, in the boldest of cases, to predict future patterns and outcomes. Whether or not it is eventually overthrown or heavily modified-and such is its fate more often than not-during its reign an accepted theory or paradigm effectively shapes discourse and research and, for better or worse, provides intellectual thrust for the collective enterprise we call a scientific or scholarly discipline.

Examples abound. Theories have been mightily influential in cosmology, chemistry, physics, political economy, genetics, demography, economics, urban geography, meteorology, oceanography, sociology, psychology, linguistics, geophysics, and history, inter alia. But when we turn to onomastics, the theoretical cupboard is bare, and progress during the past fifty years or so has been virtually nil. In fact, just about the only activity that might conceivably aspire to the dignity of being called theoretical is the seemingly never-ending effort on the part of some of our brightest colleagues to construct a precise definition of proper nouns, or names. But the definitional endeavor represents the most rudimentary of steps in any field of study, i.e., setting forth the bounds of the subject. Thus, in a special issue on "Theory About Names" in Vol. 33, No. 3 of Names, four of the five essays dealt with the definitional dilemma and only one (Algeo 1985) with larger theoretical issues. Then, of the 239 articles in a more recent, truly compendious handbook of onomastics (Eichler et al. 1996), only four are devoted to "Elements of a General Theory of Names." Two of these treat the venerable problem of defining a proper noun, while the other two explore the relevance of existing communication and general linguistic theories. None are directed toward a meaningful theory of names. To the best of my knowledge, the only substantive efforts that move beyond definition, that most elemental of exercises, are scattered experiments in classifying names, about which more anon.

What I propose to do here, with maximum trepidation, is to offer a plausible explanation for the theoretical backwardness of our field and to suggest the initial steps toward a remedy.

Two factors may account for the theoretical sterility of onomastic scholarship. The first has already been alluded to: the obsession with achieving a rigorous definition of names, staking out that elusive boundary between proper and common nouns. I do not intend to review the relevant literature (in part because to do so might expose my 
intellectual limitations). Much of it is highly technical in character, and, after several decades of intense cerebration, the pursuers of their holy grail of an ironclad definition seem no closer to the goal than they were at the outset. ${ }^{1}$

As Stewart and Pulgram $(1971,1157)$ have concluded, "the impossibility of a distinction between names (proper names) and ordinary nouns (common names) becomes evident." Although the person on the street may get along quite nicely with the OED definition, "The particular combination of sounds employed as the individual designation of a single person, animal, place, or thing," it is wholly inadequate for the demanding scholar. On the other hand, the final formulations emanating from various laborious inquiries into the nature of names can verge on the incomprehensible. The following definition offered by Ernst Pulgram is among the least opaque, but, after a half dozen perusals, I remain uncertain as to exactly what it means or how it should be used:

\begin{abstract}
A proper name is a noun used . . . in a non-universal function, with or without recognizable current lexical value, of which the potential meaning coincides with and never exceeds its actual meaning, and which is attached as a label to one animate being or one inanimate object (or to more than one in the case of collective names) for the purpose of specific distinction from among a number of like or in some respects similar beings or objects that are either in no manner distinguished from one another or, for our interest, not sufficiently distinguished $(1954,49)$. (For what it may be worth, my private personal definition is "a one-word poem in an undeciphered tongue.)
\end{abstract}

Clearly it is time to throw up our hands and admit to stalemate or defeat, to recognize the intractability of the problem while turning to more promising avenues of cogitation. By its very nature, the domain of names is fuzzily bounded. There will always be a large company of terms falling into the twilight zone between genuine namefulness and the mass of ordinary (in English at least) lowercase words. It may well be that onomastics is unique among all scholarly enterprises in its definitional frustration. In any case, I cannot think of a comparable situation in any other field. Thus the student of hydrology has a pretty clear notion as to what is a stream and what is not; the political geographer need not tarry long in deciding what entities are sovereign states; and so on.

Perhaps the best way to illustrate the deleterious impact of the squishiness of the name/non-name boundary is to consider a counter-historical example. The field of urban studies, one shared by sociologists, 


\section{Names 50.4 (December 2002)}

geographers, economists, and planners, among others, has been thriving for the past hundred years or so. During most of that period, there has been relatively little concern as to just what constituted a city or what did not. As of 1900 , virtually everywhere in the world, urban places were clearly set off from the countryside, sometimes in stark physical terms with a wall. The researcher could, and did, pursue description, analysis, and theorizing with nary a worry about how to circumscribe the objects at hand. But imagine, if you will, what might be happening if the various fields of urban studies had not originated until the 21st century. Today, throughout the so-called advanced countries of the First World but also to some extent in developing lands, the city has lost its singularity, its definite shape and limits, as suburbanization, exurbanization, and the flow of urban ideas, attitudes, and other influences deep into the rural hinterland have proceeded so vigorously. Delimiting the city has become a virtually impossible task, and would probably severely stymie the forging of theoretical concepts on the part of pioneering students of urban phenomena were they first encountering them in 2002.

\section{The Sociology of Onomastics}

But a second factor may be more to blame for the sorry state of onomastic theory than our inability to pin down precisely what it is we are observing: the sociology of knowledge. For whatever reasons (and I have none to present), the number of serious students of names has always been relatively limited. ${ }^{2}$ Moreover, onomastics has been an academic orphan (Murray 1994). In a manner somewhat analogous to genealogy, many of its practitioners have been dedicated laypersons, usually self-trained and self-motivated. Within institutions of higher learning, rarely, even on the largest of North American campuses, do we find more than a single student of names. And of necessity, given the nature of their appointments, such scholars can pursue onomastics only on a part-time basis.

Although, as already noted, the study of names impinges upon a wide variety of disciplines, including linguistics, philosophy, sociology, psychology, anthropology, history, geography, law, and literary studies, we have never seen a Department of Onomastics established at an American college and undergraduate courses on the topic are notably rare. Nor have we witnessed the creation of any interdisciplinary institute or the like devoted to studying names at any American university, a 
device that has been the salvation of demography, otherwise another academic orphan. Onomastics seems to claim a firmer foothold in Scandinavian schools and some in Eastern Europe (Nicolaisen 2002). But, given my secondhand knowledge of the European situation, I am in no position to speculate as to why serious overseas ventures into theory have not yet materialized. Pursuing the comparison with demography, a field with which I have more than a passing acquaintance, despite the absence of degree-granting undergraduate departments, there are several postgraduate interdisciplinary programs and, at the national and international levels, bureaucracies that not only gather and disseminate data but also engage in analysis and sophisticated research. The parallel name-related organizations in national capitals confine themselves to data-gathering and adjudication of disputes.

Although we do have periodic regional, national, and international conclaves and various periodicals, they do not suffice for the isolated lay or academic name lover. Nothing can substitute for having a critical mass of likeminded persons in daily or frequent contact who can generate intellectual ferment and ultimately theoretical forays, the happy situation prevailing for so many other disciplines within Academe. Add to this sorry lack the fact-one that is both the glory and bane of onomasticsthat it falls between so many stools, yet claims no sizeable portion of any established discipline's personnel and you have a basic reason for the theoretical doldrums in which we find ourselves. ${ }^{3}$

Were it not for the sociology of name studies-most notably the fragmentation of its practitioners-it would seem passing strange that no one has even begun to collate all those countless localized, time-bound studies of personal naming from so many parts of the world in order to create a systematic typology or an analytical conspectus of the practices in question. In a precisely parallel situation, that is what anthropologists have triumphantly executed with their data on kinship and marital patterns from hither and yon. Indeed the results have greatly enriched our theoretical understanding of the ways in which human societies in general happen to operate. The same observation applies to the superabundance of material on place names: a huge stockpile of information simply sitting there in isolated heaps. And has anyone ever dreamed of the possibility of somehow merging our overflowing treasure troves of personal name treatments with all those place name studies to see what fresh insights or questions such an intermingling of resources might generate? 


\section{Names 50.4 (December 2002)}

\section{Proposed Taxonomy}

Obviously no overnight solutions are feasible as far as organizational and manpower matters are concerned. Instead the course of action would seem to be to husband and focus our limited intellectual resources into more productive channels. To this end I propose moving beyond or around the most rudimentary of scholarly endeavors, a definitional morass that seems interminable. That means progressing to an exercise common to most budding disciplines: the "Linnean Phase," i.e., cataloguing and arranging all the objects under investigation into some logical, coherent classificatory scheme. Such a typology, or taxonomy, may have theoretical implications, as was most powerfully the case in the biological sciences, or it may not. But without such a resource theoretical advances are difficult to envision.

It is disappointing and sobering to realize that to date no one has essayed a serious, comprehensive taxonomic scaffolding for the vast and varied universe of names. As far as I am aware, there have been only two rather sketchy gestures toward such an objective. The first, a tenpart scheme proposed by Stewart and Pulgram $(1971,1157)$ some three decades ago, though far from exhaustive, is certainly thought-provoking and merits summarizing here:

\section{Personal names;}

2. Quasi-personal names (as for pets, dolls, ships);

3. Names for things not definitely personified but individualized (e.g., marker stones or trees);

4. Place names;

5. Names of tribes, groups, etc.;

6. Names of institutions and corporations;

7. Titles, i.e., the names of books and other works of art;

8. Brand names, e.g., Coca Cola, Vaseline;

9. Names of events in history, e.g., the Sicilian Vespers, the Renaissance;

10. Names of abstractions not personified, e.g., Stoicism.

I would question only the final category, another example of the definitional quandary.

The other precedent is to be found in Frank Nuessel's The Study of Names (1992). Although more than half its pages are devoted to anthroponyms and toponyms, it also allots space in systematic fashion to brand names, trade names, corporate names, diseases and syndromes, call letters, athletic teams, rock and roll band names, tropical storms, animal 
names, train names, scientific nomenclature, military code names, names for awards, and drink names. But, once again, coverage is partial.

In my lengthy appendix, I have earnestly sought to be as comprehensive as possible, to include every group of words that reasonable scholars could accept as names. Such a policy has meant the exclusion, quite reluctantly, of debatable categories such as the terms applied to objects studied by physical scientists, namely chemical elements (but see Ellis 1953), chemical compounds, minerals, and soil types. (Although tin and silver are clearly common nouns, one can imagine a plausible brief on behalf of the namefulness of such transuranic elements as berkelium and einsteinium.) In a few cases, I have granted qualified admission to items that could fall on either side of the proper/common noun divide, indicating their anomalous status by the use of brackets. Note also that the appendix is time-specific, reflecting knowledge of the observable world as of the time of writing. A fair number of the categories listed did not exist, or were not recognized, in the not too distant past. Consequently, we can expect additional name-types in the future as society, technology, and learning continue to evolve.

The items in the appendix are arrayed within eight grand divisions, including a final batch of otherwise unclassifiable terms. And there is further subdivision within the primary groups, sometimes as far as three levels down the hierarchy, yielding a total of more than 130 name-types. I would hazard the conservative guess that personal and place names account for at least $98 \%$ of the existing literature, so I have taken special pains to identify the many understudied or totally neglected reaches of the onomastic domain. Where useful treatments of items within the latter group are available, publications with scarcity value, I have cited them in the appendix.

The order in which both the larger and smaller divisions are presented is quite arbitrary, so that one should not read any particular significance into the sequence. Once again, the general absence of citations in II-A (personal names) and in III (place names) indicates that most of the subtopics have been dealt with so frequently that citations are superfluous. In other instances, notably for celestial objects and scientific nomenclature for organisms, naming procedures are so standardized, so cut-and-dried, that neither citation nor detailed analysis is called for.

Not to be overlooked is the fact that not every observable object with some claim to individuality is nameworthy. Thus we never assign names to sunsets, no matter how brilliant, to an above-average snowfall, to 
birthday parties, or even the most exceptional of traffic jams. An adequate theory of names should supply an explanation as to what constitutes the threshold of nameworthiness.

It must be admitted that, unlike the taxonomies in the natural sciences, the scheme offered here is rife with ambiguities. That is to say, a given name-type can logically appear within two or more of the larger categories. Church names furnish a striking example. They can be allotted to either the settlement landscape, the class of structures, enterprises, or to that of social entities with equal propriety. This porosity, or intertwining of categories, as well as the very nature of the phenomena in question, suggests, as Algeo (1985) has argued, that, whatever tentative theory emerges from further research and discussion, it will necessarily be characterized as "weak theory," one lacking predictive power, among other attributes.

\section{The Steps Beyond Taxonomy}

We have won only half the descriptive battle whenever we arrive at a thorough, logical inventory and ordering of the uncountable millions of names of which we have some record. Just as in the case of describing and cataloging plants and animals, students of names must devise some sort of protocol for characterizing each occurrence within a given nametype. If biologists have agreed upon standardized physical criteria for identifying, measuring, and describing specimens that generally work wonderfully well, such metrical systems are inappropriate for names.

In the limited number of instances in which analysts of names have classified their subject matter, the approach has invariably been to arrange them in terms of mode of origin rather than morphology. By "mode of origin" I mean reference to such things as the physical attributes of the named object, its location, the name of its proprietor, image-enhancement, or the intent to amuse. We find existing classificatory schemes of varying degrees of complexity for the following types: personal names (Pulgram 1954, 12), place names (McArthur 1986; Nuessel 1992; Stewart 1954), streets (Baldwin and Grimaud 1989; Fairclough 1974; Pillsbury 1969), real estate developments (Minton 1959), apartment houses (Koegler 1980), churches (Zelinsky 2002), cemeteries (Zelinsky 1975; 1990), retail establishments (Raento and Douglass 2001; Wilhelm 1988), auto brand names (Piller 1999), trucks (Kus 1979), associations (Ridinger 1998), and business firms (Walasek 1983). 
The number of descriptors within each scheme varies greatly, ranging from a minimum of four to more than twenty. Moreover, no two systems are identical or even closely comparable. It is all too clear that ad hockery reigns supreme, that each researcher has been obliged to reinvent the wheel, so to speak. To put it mildly, such a situation is both inefficient and exasperating.

Is it possible to consider fabricating a single universal system for profiling names of every sort, one necessarily based on mode of origin? I believe the answer to be yes, even if the process would not be easy or painless. I also believe that such a project is beyond the capabilities of any single individual no matter how erudite or enterprising. What is called for is a collaborative effort, a task for a small select committee whose members' collective expertise spans as much as is practical of the full range of the world of names. Arduous though the chore would be, the eventual payoff would be immense.

If such a project were to come to fruition, the result would be a standard checklist covering in logical fashion all significant ways in which names can be invented. When such a master grid would be applied to any specific set of names, more often than not one would find a fair number of empty cells while the tabulation would skew toward a limited number of options. But such emptinesses, and overloading in some areas, would provide clues to larger verities.

I would also urge that, in addition to adhering to a standardized, universal mode of classification, the investigator should also take note of, and record, a number of parameters that help characterize a particular family of names. How large a population is being considered? Is it seemingly finite (as in names of sovereign states) or virtually open-ended (as in personal names)? What is its geographical extent-localized or global? How official, i.e., regulated by governmental or other formal agencies, or vernacular in character? How durable are these usages -ranging from the ephemeral, such as nicknames, to the eternal, as in scientific nomenclature for stars and organisms? These parameters should also be determined by the proposed committee.

The ultimate benefits of the proposed procedure would not begin to emerge until researchers have applied it to a fairly wide and diverse array of name-types from many localities, cultures, and historical eras, so that we could then begin cross-tabulating the many different patterns of mode of origin. Superimposition of a multiplicity of profiles-and there can't be too many-could yield unpredictable insights into the inner 


\section{Names 50.4 (December 2002)}

workings of the naming process and fresh questions to be solved en route to our theoretical destination.

\section{In Summary}

Let me summarize the approach I have been preaching here. In terms of future data gathering and processing, everything hinges on the critical first step: a standardization of the classification system for items within each discrete category of names. Such a format should be the product of deliberation by a select committee. After the successful drafting of such an instrument, it should be applied to all subsequent inquiries, whatever sorts of names might be at play. Moral suasion exerted by all relevant scholarly organizations could be decisive in attaining such uniformity of practice.

Next, it is imperative that we begin filling in the blanks. We must gather, classify (using the approved procedure), and analyze all those many groups of names that remain poorly known or totally unexplored, and do so in as many parts of the world and over as many time periods as may be feasible.

Then, at some point in the not too remote future, one trusts, we may be able to begin collating usages within and among a large variety of name-types, then begin extracting whatever structural principles underlie the naming process. Such a task may well be feasible already for our best-studied categories: personal names and place names. Despite the absence of any uniform mode of classification being observed in our vast multitude of studies, it may still be possible to distill some useful generalizations within each of the two categories and-it may not be too much to hope-from their merger.

Finally, after we have accumulated sufficient analyses of a wide assortment of name-types, we can begin posing hypotheses bold enough to cover the entire field. In such an ascent toward a genuine (if weak) theory of names, we would do well to keep peering over our shoulders at the theoretical landscape in the fields of linguistics, communication, and psychology. We might discern some commonalities.

If we were to act upon the suggestions set forth in this paper, then we would have passed beyond the first two of the seven steps in John Algeo's (1985, 143-144) proposed journey toward a weak theory of names, setting aside the first but consummating the second, and be prepared to assault the remaining five, but especially the final pair, as follows: 
1. Define the concept of name;

2. Provide taxonomies of names;

3. Deal with historical and current manifestations of names;

4. Distinguish competence versus performance in name usage;

5. Differentiate onomastic theory from theories applied to related disciplines;

6. Relate onomastics to the larger sphere of human activity and behavior;

7. Seek universal properties in naming strategies.

I would argue further that completing such a program would redound not only to the health and glory of our orphan discipline but, on a much wider plane, to the general vitality of all the humanities and social sciences.

This has been as much a call for further discussion and argument as a fully confident manifesto. I invite comment and rebuttal.

Appendix

\section{A Preliminary Typology of Names*}

I. Deities (Knobloch 1996a; Polomé 1996)

II. Biota

A. Human beings

1. Official or customary names

2. Nicknames

3. Pseudonyms, stage names, noms de plume, aliases

4. Fictional characters

5. Saints (Knobloch 1996b)

6. Persons in religious orders

7. Quasi-humans, e.g., dolls

8. [Numbers assigned to prison inmates, members of the military, or ordinary citizens, as in Social Security numbers]

B. Plants, animals, other organisms

1. "Wild" organisms, scientific designations thereof

a. Historic trees

2. Fictitious or imaginary animals and plants

3. Copyrighted or commercial names for ornamental and agricultural plants

4. Pets (Dobnig-Jülch 1996)

5. Mascots

6. Show and racing animals (Ashley 1996b)

7. [Diseases, medical syndromes] 
254 Names 50.4 (December 2002)

III. Places

A. Celestial objects

1. Satellites

2. Asteroids

3. Comets

4. Stars

5. Constellations

6. Galaxies

B. Extraterrestrial place names on

1. The moon

2. Mars

3. Other planets and/or their satellites

C. Terrestrial features

1. Natural or artificial physical features including mountains and peaks; hills; valleys; passes; glaciers; deserts; streams; lakes and ponds; swamps and marshes; caves; faults; beaches, bays, coves, capes, and other shoreline features; reefs and other marine features; winds; etc.

a. Historic rocks

2. Political and administrative jurisdictions (Back 1996)

3. Settlements

a. Cities, suburbs, towns, villages, hamlets

b. Neighborhoods

c. Residential subdivisions (Minton 1959; Norris 1999)

4. Shopping centers

5. Streets, alleys, highways, lanes, trails (Fairclough 1974;

Baldwin and Grimaud 1989; Handke 1996; Pillsbury 1969;

Tarpley 1996; Fuchschuber-Weiss 1996)

6. Plazas, squares, dedicated corners

7. Railways

a. Railway and subway stations and stops

8. Canals

9. Pipelines 
10. Churches, convents, monasteries

11. Cemeteries (Zelinsky 1975, 1990)

a. Sections and lanes thereof

12. Playgrounds

13. Gardens, arboreta

14. Parks, forests

15. Mines, quarries (Hellfritzsch 1996b)

16. Resorts, country clubs, ski facilities

a. Ski trails

17. Farms, ranches

a. Wineries

b. Fields

18. Military facilities

19. Survey points

20. Imaginary places

IV. Events
A. Geological epochs
B. Historical eras
C. Wars, military campaigns
D. Battles
E. Space missions
F. Hurricanes, typhoons, and major floods
G. Major earthquakes
H. Major fires
I. Tournaments, races, other major sporting events
J. Festivals and other special celebrations (Jeske 1996)
V. Social Entities
A. Nations, ethnic groups (Herbert 1996; Rubekeil 1996)
B. Religious denominations, religious orders
1. Congregations
C. Voluntary associations (Ridinger 1998)
D. Social clubs
E. Military units
F. Fire companies 


\section{Names 50.4 (December 2002)}

VI. Enterprises

A. Business firms (Walasek 1983)

1. Divisions within corporations

B. Nonprofit enterprises

C. Retail and wholesale businesses (Hellfritzsch 1996a; Jehle 1996; Raento and Douglass 2001; Steiner 1986; Wilhelm 1988)

1. Named rooms within restaurants, night clubs, etc.

D. Churches (Zelinsky 2002)

E. Government agencies

F. Radio and television stations

G. Athletic teams

H. Musical, dance, dramatic, and other performing groups; vaudeville acts

VII. Artifacts

A. Structures

1. Government and other public buildings

2. Office buildings

3. Commercial buildings

4. Convention centers

5. Residences

a. Single-family homes

b. Second homes, vacation cottages, trailers

b. Apartment houses (Koegler 1986); hotels (Jehle 1996), motels

1. Named rooms and suites within hotels and convention centers

c. Retirement/nursing facilities

6. Primary and secondary schools (Lotscher 1996); daycare facilities

7. Colleges

a. Buildings within college campuses

8. Churches, convents, monasteries (Reitzenstein 1996), retreats

9. Castles, forts (Boxler 1996) 
10. Shrines

11. Factories, warehouses

12. Stadia, racetracks, amusement parks

a. Rides within amusement parks

13. Libraries

14. Hospitals

a. Dedicated rooms or wings

15. Prisons

16. Fire stations

17. Airports

18. Bridges and tunnels

19. Dams

20. Asylums

21. Fountains

B. Vehicles

1. Ships and boats (Ashley 1996a; Kuba 1996)

2. Trains

a. Named railway cars

3. Aircraft

4. Space craft

5. Individual automotive vehicles

a. Automobiles; vanity plates

b. Buses

c. Trucks (Kus 1979)

d. Motorcycles

C. Weapons systems

D. Literary and other expressive works

1. Books

a. Chapter titles

2. Periodicals

3. Articles in periodicals

4. Poems

5. Orations, sermons

6. Musical compositions

a. Titles of movements 
258 Names 50.4 (December 2002)

7. Operas

8. Dances and ballets
a. Dance steps

9. Paintings

10. Sculptures

11. Maps

12. Films

13. Radio and television shows

14. Phonograph albums, cassettes, and compact discs

E. Monuments

F. Commodities and their brand names (Koss 1996)

G. Famous musical instruments

H. Famous gems

I. Major telescopes

J. Names for coins and currency

VIII. Unclassifiable
A. Awards, prizes
B. Statutes, treaties
C. Telephone exchanges
D. Scientific laws
E. Recipes; mixed drinks
F. Poker hands (Clark 1986)
G. Map projections

*Bracketed items are those whose status as proper names is debatable.

\section{Notes}

It is not customary for scholars to disclose the intimate details of conception and parturition when displaying their wares. But, in the event anyone is curious, I vividly recall the moment on the morning of December 1, 2001 when the impulse for this essay flashed into my mind. The immediate impetus was irritation over having to concoct yet another ad hoc scheme for classifying names, in this instance one for names of churches (Zelinsky 2002). But, upon further reflection, I now realize I owe the inspiration for this effort to the late, great George R. Stewart, who expressed his aspirations for onomastics in a 1953 statement in the inaugural issue of Names. Various of his other writings revealed an unhappiness over the primitive level of onomastic theory that had also been festering subterraneously within me for quite a few years. Consider these pages my homage to a remarkable thinker, scholar, and creative writer. 
1. The literature dealing with the problematic nature of names and how to arrive at a satisfactory definition is too large for a full listing, while a discussion thereof would be too long and tedious for inclusion here. But a representative sample would include Algeo (1973), Grodzinski (1980), Nicolaisen (1976; 1985), Pamp (1985), Pulgram (1954), Willems (2000), and Zgusta (1998). Especially illuminating and worthy of mention is a compendium by the indefatigable Eric Partridge (1940) of English language terms that have oozed their way from the domain of proper names into our repertoire of lower-case words.

2 . We can assign a certain amount of blame to the relative youth of our field as compared to the generally accepted academic disciplines. On the other hand, the equally recent field of American Studies has attained departmental status at a fair number of colleges.

3. To pursue the not-quite-parallel case of demography a bit further, it happens that a solid plurality of scholars with demographic inclinations have been housed within departments of sociology. That fact has certainly sustained the vitality of demographic studies.

\section{References}

Algeo, John. 1973. On Defining the Proper Name. Gainesville: Univ. of Florida Press.

. 1985. "Is a Theory of Names Possible?" Names 33: 136-144.

Ashley, Leonard R. N. 1996a. "Humorous Names of US Pleasure Craft." In Eichler, et al., 1582-1583.

1996b. "Names of Racehorses in the United Kingdom and the United States." In Eichler, et al., 1589-1590.

Back, Otto. 1996. "Typologie der Landernames: Staaten-, Lander-, Landschaftsnamen." In Eichler, et al., 1348-1356.

Baldwin, Lawrence M. and Michael Grimaud. 1989. "The Street Naming Systems of the United States." Names 37: 115-138.

Boxler, Heinrich. 1996. "Burgnamen." In Eichler, et al., 1596-1601.

Clark, Thomas L. 1986. "Noms de Felt: Names in Gambling." Names 34: 11-29.

Dobnig-Jülch, Edeltraud. 1996. "Namen von Haustieren und Zuchttieren." In Eichler, et al., 1583-1589.

Eichler, Ernst, Gerold Hilty, Heinrich Löffler, Hugo Steger, and Ladislav Zgusta, eds. 1996. Namenforschung; Proper Names; Les Noms Propres. Berlin and New York: Walter de Gruyter.

Ellis, Fred, Jr. 1953. "Naming of Chemical Elements." Names 1: 163176. 


\section{Names 50.4 (December 2002)}

Fairclough, G. Thomas. 1974. "Toward a Systematic Classification of Street Name Patterns in U.S.A. and Canadian Cities." In They Had

to Call It Something, Fred Tarpley, ed. Commerce, TX: Name Institute Press, 65-76.

Fuchschuber-Weiss, Elisabeth. 1996. "Strassenamen: Deutsch." In Eichler, et al., 1468-1476.

Grodzinski, Eugeniusz. 1980. "Proper Nouns, Common Nouns and Singular Descriptions." Onoma 24: 10-15.

Handke, Kwiryna. 1996. "Strassennamen: Slavisch." In Eichler, et al., 1476-1481.

Hellfritzsch, Volkmar. 1996. In Eichler, et al. 1590-1593.

Herbert, Robert K. 1996. "Some Problems of Ethnonyms for NonWestern Peoples." In Eichler, et al., 1343-1348.

Jehle, Lorenz. 1996. "Gasthausnamen " In Eichler, et al., 1601-1606. Jeske, Hans. 1996. "Namen von Wochentagen, Jahreszeiten, Festen und Jahrmarkten." In Eichler, et al., 1659-1665.

Knobloch, Johann. 1996a. "Namen Gottes und der Engel." In Eichler, et al., 1846-1852. . 1996b. "Namen Christlicher Heiliger." In Eichler, et al., 18561860.

Koegler, Karen. 1986. "A Farewell to Arms: The 'Greening' of American Apartment Names," Names 34: 48-61.

Koss, Gerhard. 1996. "Warennamen." In Eichler, et al., 1642-1648.

Kuba, Ludvik. 1996. "Namen von Fahrzeugen." In Eichler, et al., 1574-1582.

Kus, James S. 1979. "Peruvian Religious Truck Names." Names 27: 179-187.

Lotscher, Andreas. 1996. "Namen von Bildungseinrichtungen." In Eichler, et al., 1606-1611.

McArthur, Lewis L. 1986. "Another Approach to Place-Name Classification." Names 7: 238-241.

Minton, Arthur. 1959. "Names of Real-Estate Developments: II." Names 7: 233-255.

Murray, Thomas E. 1994. "On the Need to Legitimize Onomastics in Academia." Names 42: 67-77. 
Nicolaisen, W.F.H. 1976. "Words as Names," Onoma 20: 142-163. . 1985. "Nomen, Noun, and Name: The Lexical Horns of an Onomastic Dilemma." In Studies in Medieval and Early Modern English, C. Groningen, ed.: Wolters-Nordhoff. . 2002. Personal Communication, 30 July.

Norris, Darrell A. 1999. "Unreal Estate: Words, Names and Allusions in Suburban Home Advertising." Names 47: 365-380.

Nuessel, Frank. 1992. The Study of Names: A Guide to Principles and Topics. Westport, CT: Greenwood Press.

Pamp, Bengt. 1985. "Ten Theses on Proper Names" Names 33: 111118.

Partridge, Eric. 1940. Names into Word: Proper Names That Have Become Common Property. London: Secker and Warburg.

Piller, Ingrid. 1999. "Variation in Automobile Naming." Names 47: 83107.

Pillsbury, Richard. 1969. "The Street Name Systems of Pennsylvania Before 1820." Names 17: 214-222.

Polomé, Edgar C. 1996. "Gotternamen der Germanen." In Eichler, et al., 1838-1846.

Pulgram, Ernst. 1954. Theory of Names. Berkeley: American Name Society.

Raento, Paulina and William A. Douglass. 2001. "The Naming of Gaming." Names 49: 1-35.

Reitzenstein, Wolf-Armin Frhr v. 1996. "Klosternamen." In Eichler, et al., 1593-1596.

Ridinger, Robert B. Marks. 1998. "Children of the Satyrs: Naming Patterns of Leather and Levi Clubs." Names 46: 97-111.

Rubekeil, Ludwig. 1996. "Volkernamen Europas." In Eichler, et al., 1330-1343.

Steiner, Rodney. 1986. "Drinking-Place Names in the Central United States." Journal of Cultural Geography 6: 19-34.

Stewart, George R. 1953. "The Field of the American Name Society." Names 1: 73-78. . 1954. "A Classification of Place Names." Names 2: 1-13. and Ernst Pulgram. 1971. "Name (in Linguistics)." Vol. 15, Pp. 1156-1163 in: Encyclopedia Britannica. Chicago. 


\section{Names 50.4 (December 2002)}

Tarpley, Fred. 1996. "Street Names as Signposts of World Cultures." In Eichler, et al., 1481-1499.

Walasek, Richard A. 1983. "The Nature of Electric Utility Company Names." Names 31: 197-206.

Wilhelm, Albert E. 1988. "Pretty Is As Pretty Says: The Rhetoric of Beauty Salon Names." Names 36: 61-68.

Willems, Klaas. 2000. "Form, Meaning, and Reference in Natural Language: A Phenomenological Account of Proper Names." Onoma 35: 85-119.

Zelinsky, Wilbur. 1975. "Unearthly Delights: Cemetery Names and the Map of the Changing American Afterworld." In Geographies of the Mind, Martyn Bowden and David Lowenthal, eds.,171-196. New York: Oxford Univ. Press. . 1990. "A Toponymic Approach to the Geography of American Cemeteries." Names 50: 83-102. . 2002. "The Names of Chicago's Churches: A Tale of at Least Two Cultures." Names 50: 83-102.

Zgusta, Ladislav. 1998. "Names." Vol. 24, Pp. 733-738 in: The New Encyclopedia Britannica. Chicago. 